\title{
Microstructure and Mechanical Properties of Cu Matrix Composites Reinforced by $\mathrm{TiB}_{2} /$ TiN Ceramic Reinforcements
}

\author{
Jinwei Yin ${ }^{1} \cdot$ Peilong Zhou ${ }^{1,2} \cdot$ Hanqin Liang ${ }^{1} \cdot$ Dongxu Yao $^{1} \cdot$ Yongfeng Xia ${ }^{1} \cdot$ Kaihui Zuo $^{1} \cdot$ YuPing Zeng ${ }^{1}$
}

Received: 27 February 2020 / Revised: 1 April 2020 / Accepted: 22 April 2020 / Published online: 9 July 2020

(c) The Chinese Society for Metals (CSM) and Springer-Verlag GmbH Germany, part of Springer Nature 2020

\begin{abstract}
$\mathrm{Cu}$ matrix composites reinforced by $\mathrm{TiB}_{2} / \mathrm{TiN}$ ceramic reinforcements $(\mathrm{Cu} / \mathrm{TBN}$ composites) were prepared by hot pressing method. Prior to the hot pressing, $\mathrm{Cu} / \mathrm{TiB}_{2} / \mathrm{TiN}$ composite powders (CTBN powders), which were used as the starting materials of $\mathrm{Cu} / \mathrm{TBN}$ composites, were fabricated by self-propagating high-temperature synthesis method. The CTBN particles were found to be in a special core-shell structure with a $\mathrm{Cu}-\mathrm{Ti}$ alloy core and a $\mathrm{TiB}_{2} / \mathrm{TiN}$ ceramic shell. The test results presented obvious improvements in mechanical properties. The highest ultimate tensile strength reached up to $297 \mathrm{MPa}, 77 \mathrm{MPa}$ higher than that of $\mathrm{Cu}$. And the highest hardness reached up to 70.7 HRF, 15.7 HRF higher than that of $\mathrm{Cu}$. A comparative study indicated that the core-shell structured particles could bring about more obvious strengthening effect than the traditional irregularly shaped particles, which was due to the improved $\mathrm{Cu}$ /ceramics interfacial bonding, the linkage strengthening effect of both $\mathrm{TiB}_{2}$ and $\mathrm{TiN}$, and higher load bearing ability of the core-shell structured reinforcements.
\end{abstract}

Keywords $\mathrm{Cu}$ matrix composite $\cdot$ Microstructure $\cdot$ Mechanical property $\cdot$ Self-propagating high-temperature synthesis (SHS)

\section{Introduction}

Copper alloy is widely applied in machinery fields because of its relatively high thermal and electrical conductivity, low cost and ease of fabrication. However, as modern machines develop toward higher speeds and higher power densities, it requires better wear resistance and mechanical properties of $\mathrm{Cu}$ alloys considering the high reliability and long service life. $\mathrm{Cu}$ matrix composites reinforced by ceramic reinforcements (CMMCs) have been proved to have superior wear resistance and mechanical properties [1-4], thus have been interesting to researchers in recent years. Titanium nitride $(\mathrm{TiN})$ and titanium diboride $\left(\mathrm{TiB}_{2}\right)$ are potential

Available online at http://link.springer.com/journal/40195.

YuPing Zeng

yuping-zeng@mail.sic.ac.cn

1 State Key Laboratory of High Performance Ceramics and Superfine Microstructure, Shanghai Institute of Ceramics, Chinese Academy of Sciences, Shanghai 200050, China

2 Center of Materials Science and Optoelectronics Engineering, University of Chinese Academy of Sciences, Beijing 100049, China reinforcements because of their outstanding mechanical properties, low densities, high melting temperature and good wear resistance. Moreover, both the two kinds of ceramics have high electrical and thermal conductivity [5], which makes them the good candidates of reinforcements in CMMCs due to their wide application in electronic parts and heat-conducting components. Titanium nitride exhibits low friction coefficient in air and in liquid because of the formation of titanium dioxide layers [6], which is quite beneficial to the improvement of wear resistance.

The traditional CMMCs are mostly reinforced by ex situ reinforcements such as $\mathrm{SiC}[7,8], \mathrm{Si}_{3} \mathrm{~N}_{4}[9,10], \mathrm{B}_{4} \mathrm{C}$ [4] et al., in other words, the ceramic reinforcements and $\mathrm{Cu}$ powders are separately prepared prior to the preparation of CMMCs. Although the ex situ routes have been successfully applied to prepare kinds of metal matrix composites (MMCs), it has several drawbacks, including poor reinforcements/matrix interfacial bonding and agglomeration of ceramics. Compared with the ex situ composites, the in situ composites have more advantages, such as thermodynamically stability of in situ formed ceramics, strong interfacial-bonding between matrix and reinforcements, uniform distribution of the ceramic particles, and good mechanical properties of composites. 
Both $\mathrm{TiB}_{2}$ and TiN can be formed via the in-situ processes in MMCs [11-14]. Chen et al. [15] prepared the $\mathrm{Cu}$ matrix composites using $\mathrm{TiB}_{2} / \mathrm{TiN}$ as the reinforcements and h-BN as the solid lubrications. According to their work, both wear resistance and hardness of the composites were improved. But the XRD patterns indicated that the amount of $\mathrm{TiB}_{2}$ generated was fairly small. Zhang et al. [16] prepared $\mathrm{TiB}_{2} / \mathrm{TiN}$ ceramics by the reaction between h-BN and $\mathrm{TiH}_{2}$ with the sintering temperature ranging from 1000 to $1600{ }^{\circ} \mathrm{C}$. They pointed that the TiN was formed at $1000^{\circ} \mathrm{C}$, but the $\mathrm{TiB}_{2}$ was not detected until the temperature was up to $1600{ }^{\circ} \mathrm{C}$. The reaction between $\mathrm{Ti}$ and $\mathrm{BN}$ was suggested to be the following:

$\mathrm{Ti}+\mathrm{BN} \rightarrow \mathrm{TiN}+\mathrm{B}$ (amor),

$\mathrm{Ti}+2 \mathrm{~B}($ amor $) \rightarrow \mathrm{TiB}_{2}$,

where the B (amor) stands for amorphous boron.

In the work of Chen et al. [15], the sintering temperature was ranging from 780 to $970{ }^{\circ} \mathrm{C}$, which was not sufficient to generate enough amount of $\mathrm{TiB}_{2}$. According to the work of Zhang et al. [16], to achieve the complete reaction between $\mathrm{Ti}$ and $\mathrm{BN}$, the sintering temperature should be higher than $1600{ }^{\circ} \mathrm{C}$. However, when the temperature is above $1600^{\circ} \mathrm{C}$, $\mathrm{Cu}$ has already has been already in liquid state (the melting point of $\mathrm{Cu}$ is $1080^{\circ} \mathrm{C}$ ). A new problem comes up: the $\mathrm{TiB}_{2} /$ TiN reinforcements may float up to the upper surface of the liquid $\mathrm{Cu}$ due to the large disparity of the densities, which results in the nonuniform distribution of reinforcements in the matrix.

In this work, the self-propagating high-temperature synthesis (SHS) method was applied to prepare CTBN powders. During the SHS process, the combustion temperature was more than $2000{ }^{\circ} \mathrm{C}$, which was sufficient for the generation of $\mathrm{TiB}_{2}$. Since the high temperature lasted quite a short time, the $\mathrm{TiB}_{2} / \mathrm{TiN}$ ceramics were adhered to the instantaneously appeared $\mathrm{Cu}$ droplets, and had no time to float up, thus the distribution of ceramics was uniform. Then, the powders were the mixed with additional $\mathrm{Cu}$ powders to fabricate $\mathrm{Cu}$ matrix composites by hot pressing. Microstructure and mechanical properties of the composites were researched to evaluate the strengthening effect.

\section{Experimental}

\subsection{Preparation of CTBN Powders}

$\mathrm{Cu}, \mathrm{Ti}$ and $\mathrm{BN}$ were used as the starting raw powders, characteristics listed in Table 1. These reactants, composition listed in Table 2, were ball milled in absolute ethanol for $24 \mathrm{~h}$. Then, the resulting slurries were dried at $60{ }^{\circ} \mathrm{C}$ for
Table 1 Characteristics of raw powder

\begin{tabular}{lll}
\hline Powder & $\begin{array}{l}\text { Grain } \\
\text { size, } d_{50} \\
(\mu \mathrm{m})\end{array}$ & Purity (\%) \\
\hline $\mathrm{Cu}$ & 20.7 & $\geq 99.5$ \\
$\mathrm{Ti}$ & 5.6 & $\geq 99.99$ \\
$\mathrm{BN}$ & 0.16 & $\geq 99.5$ \\
\hline
\end{tabular}

Table 2 Composition of the raw materials for the SHS process

\begin{tabular}{llll}
\hline Products & \multicolumn{3}{l}{ Composition of the raw materials } \\
\cline { 2 - 4 } & $\mathrm{Cu}(\mathrm{g})$ & $\mathrm{Ti}(\mathrm{g})$ & $\mathrm{BN}(\mathrm{g})$ \\
\hline A-CTBN & 0 & 143.6 & 49.6 \\
B-CTBN & 143.6 & 143.6 & 44.6 \\
$\mathrm{C}-\mathrm{CTBN}$ & 143.6 & 143.6 & 49.6 \\
D-CTBN & 143.6 & 143.6 & 54.6 \\
E-CTBN & 143.6 & 143.6 & 59.6 \\
\hline
\end{tabular}

$3 \mathrm{~h}$ to remove ethanol followed by pulverizing and passing through a 100 mesh sieve. After that, the mixtures were put in a BN-coated graphite crucible. A tungsten heating coil was used to ignite the reaction of titanium powders and BN powders. The combustion reaction process proceeds in the SHS furnace using Ar as the protective atmosphere. After the reactions, the samples were removed from the combustion synthesis vessel. The products were pulverized and passed through a 100 mesh sieve to obtain uniform and refined powders. The produced powders in Table 2 are labeled as A-CTBN, B-CTBN, C-CTBN, D-CTBN and E-CTBN, respectively.

\subsection{Preparation of $\mathrm{Cu} / \mathrm{TBN}$ Composites}

The C-CTBN powders fabricated by SHS process were selected as the reinforcement phases to prepare the $\mathrm{Cu} / \mathrm{TBN}$ composites, because $\mathrm{BN}$ and $\mathrm{Ti}$ in this group can completely react with each other according to stoichiometric ratio. Additional $\mathrm{Cu}$ powders mixed with the C-CTBN powders were ball milled by planetary ball milling for $3 \mathrm{~h}$ to form the uniform mixtures. After that, the mixtures were dried at $60{ }^{\circ} \mathrm{C}$ for $3 \mathrm{~h}$ to remove ethanol followed by pulverizing and passing through a 100 mesh sieve. The resulting powder mixtures were hot pressed in a graphite die under a uniaxial load of $25 \mathrm{MPa}$ in vacuum. The composites were sintered at two different sintering temperatures $\left(1000{ }^{\circ} \mathrm{C}\right.$ and $\left.1030{ }^{\circ} \mathrm{C}\right)$ for $2 \mathrm{~h}$.

X-ray diffraction (XRD, D8 discover, Bruker, Germany) was applied to analyze the phase composition of the powders and the composites. Scanning electron microscopy (SEM, JSM-6390, JEOL, Japan) was applied to characterize 
microstructures of CTBN powders and fractured surfaces of $\mathrm{Cu} / \mathrm{TBN}$ composites.

Densities of composites were measured using Archimedes method in deionized water as an immersion medium. Theoretical density of composites was calculated by the following equation:

$\rho_{\mathrm{th}}=\rho_{\mathrm{TBN}} V_{\mathrm{TBN}}+\rho_{\mathrm{Cu}} V_{\mathrm{Cu}}$,

where $\rho_{\mathrm{th}}, \rho_{\mathrm{TBN}}$ and $\rho_{\mathrm{Cu}}$ were the theoretical density of composites, $\mathrm{TiB}_{2} / \mathrm{TiN}$ ceramics and $\mathrm{Cu}$ matrix, respectively; $V_{\mathrm{TBN}}, V_{\mathrm{Cu}}$ were the volume fraction of $\mathrm{TiB}_{2} / \mathrm{TiN}$ ceramics and $\mathrm{Cu}$ matrix. All the $\mathrm{TiB}_{2} / \mathrm{TiN}$ content mentioned in this work represented the mass fraction of only $\mathrm{TiB}_{2} / \mathrm{TiN}$ in the $\mathrm{Cu} / \mathrm{TBN}$ composites, and the share of $\mathrm{Cu}$ in $\mathrm{CTBN}$ powders was included in the $\mathrm{Cu}$ matrix. The relative density $(R)$ was achieved by the following equation:

$R=\rho_{\text {ar }} / \rho_{\text {th }}$,

where $\rho_{\text {ar }}$ was experimental density achieved by Archimedes method.

Tensile strength was measured using a universal testing machine (Instron-5566, Instron, USA) with a tensile rate set at $3 \mathrm{~mm} / \mathrm{min}$. Each final value of tensile strength tests was the average of six measurements. Hardness tests were conducted on polished samples using Rockwell hardness tester (Wilson-2000, Instron, USA), and the load of $60 \mathrm{~kg}$ was applied by the spherical indenter of $1.58 \mathrm{~mm}$ in diameter.

\section{Results and Discussion}

\subsection{Compositions of the CTBN Composite Powders}

The XRD patterns of the CTBN powders are presented in Fig. 1. Compositions of the raw materials are listed in Table 2. Since $\mathrm{TiB}_{2}$ and $\mathrm{TiN}$ peaks can be found in all the groups, it confirms that the $\mathrm{TiB}_{2}$ and $\mathrm{TiN}$ phases have been successfully formed via the reaction between $\mathrm{Ti}$ and $\mathrm{BN}$ during the SHS process. The inexistence of $\mathrm{BN}$ in the B-CTBN patterns indicates that the $\mathrm{BN}$ is completely exhausted by the reaction with $\mathrm{Ti}$ to convert into $\mathrm{TiB}_{2}$ and $\mathrm{TiN}$. Although the amounts of BN and Ti in A-CTBN and C-CTBN are coincide with the reaction stoichiometric ratio, $\mathrm{BN}$ peaks still can be found in both patterns, which means that the reaction is incomplete and residual Ti may diffuse into the $\mathrm{Cu}$ particles to form $\mathrm{Cu} / \mathrm{Ti}$ alloy. In D-CTBN and E-CTBN, the $\mathrm{BN}$ is excessive for the reaction with $\mathrm{Ti}$, and the peaks of $\mathrm{BN}$ can be still detected.

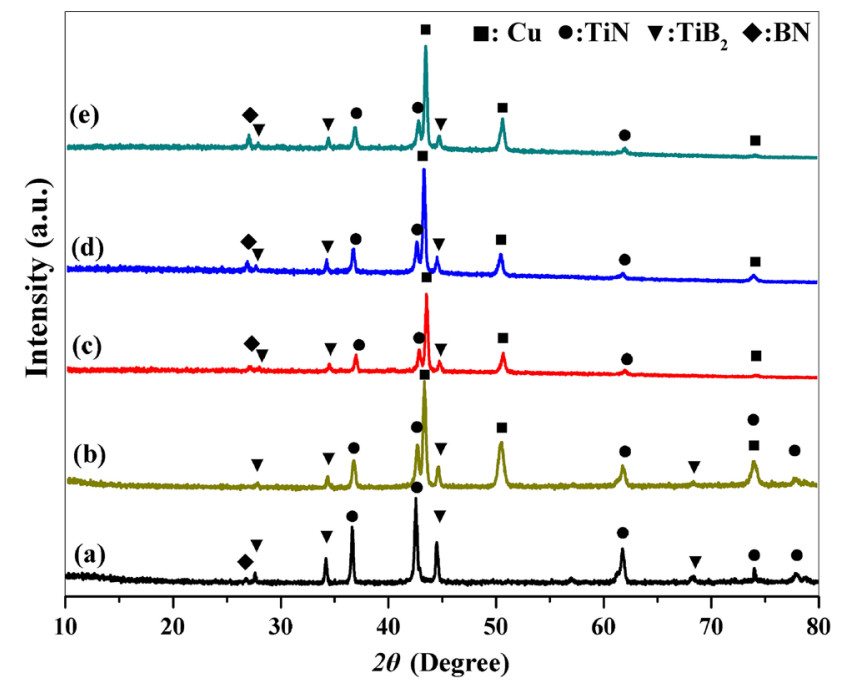

Fig. 1 XRD patterns of the CTBN powders: (a) A-CTBN, (b) B-CTBN, (c) C-CTBN, (d) D-CTBN, (e) E-CTBN
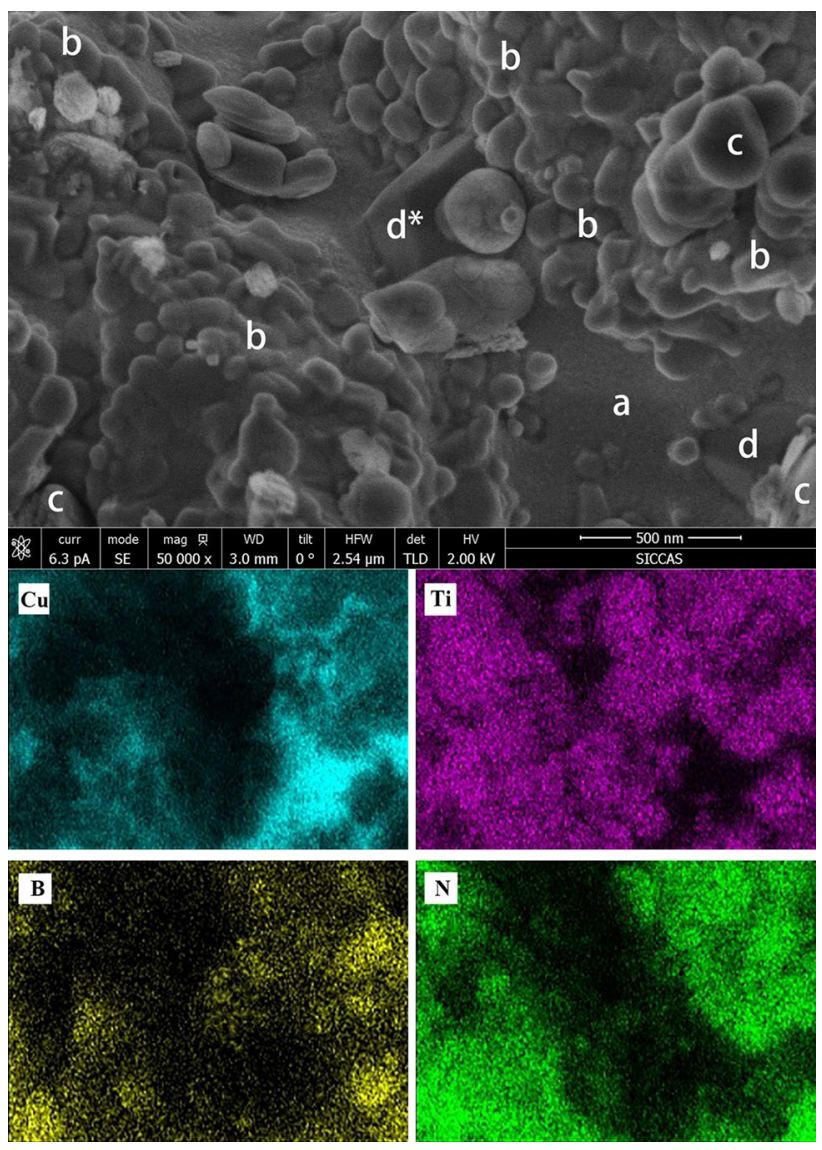

Fig. 2 Microstructure of C-CTBN powder, and EDS mapping results of $\mathrm{Cu}, \mathrm{Ti}, \mathrm{B}$ and $\mathrm{N}$ 


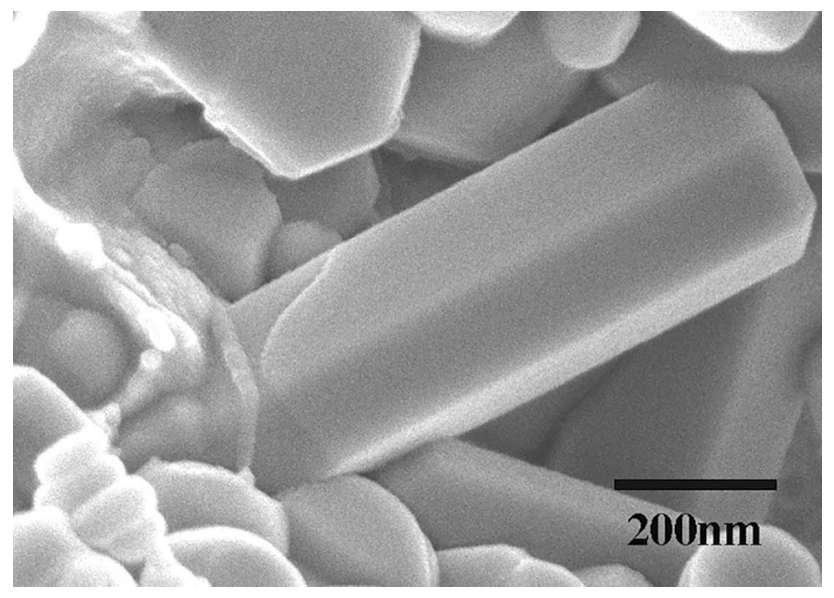

Fig. 3 Typical hexagon clubbed structure of $\mathrm{TiB}_{2}$ particle

\subsection{Microstructures}

Figure 2 shows the micrograph of the C-CTBN powders. According to the energy disperse spectroscopy (EDS) mapping tests, the smooth background labeled "a" in Fig. 2 is detected to be $\mathrm{Cu}$, and is covered by various small particles. The small spherical particles labeled "b" in diameter of dozens of nanometers are mostly TiN, which can be proved by the EDS mapping tests $(\mathrm{Ti})$ and $(\mathrm{N})$. The spherical particles labeled "c", a bit larger than "b", are $\mathrm{BN}$ according to the EDS mapping tests (B) and (N). The large particles embedded into the $\mathrm{Cu}$ metal should be $\mathrm{TiB}_{2}$, which coincide with the EDS mapping tests (Ti) and (B). The $\mathrm{TiB}_{2}$ particles generated during the SHS process are hexagon and clubbed particles as shown in Fig. 3, which is partly buried into the $\mathrm{Cu}$ matrix. According to the research by Yang et al. [17] and Xinghong et al. [18], the clubbed structured $\mathrm{TiB}_{2}$ with high aspect ratio was very effective to improve the mechanical properties and wear resistance of composites.

\subsection{Densification}

Figure 4 shows the change of relative densities of $\mathrm{Cu} / \mathrm{TBN}$ composites with different $\mathrm{TiB}_{2} / \mathrm{TiN}$ contents. Densities of the composites in both groups present a steady decrease with $\mathrm{TiB}_{2} / \mathrm{TiN}$ content increasing from 0 to $4 \mathrm{wt} \%$. Obviously, the ceramic reinforcements are the major factors inhibiting densification of the composites. Although the ceramics are partly embedded into the $\mathrm{Cu}$ particles during the SHS process, plenty surfaces of ceramics are exposed. These exposed particles can weaken mass transfer by pinning effect thus to block the connection between $\mathrm{Cu}$ particles. And the relatively poor wettability between $\mathrm{Cu}$ matrix and ceramics can further enhance the inhibition $[19,20]$. As a result, the

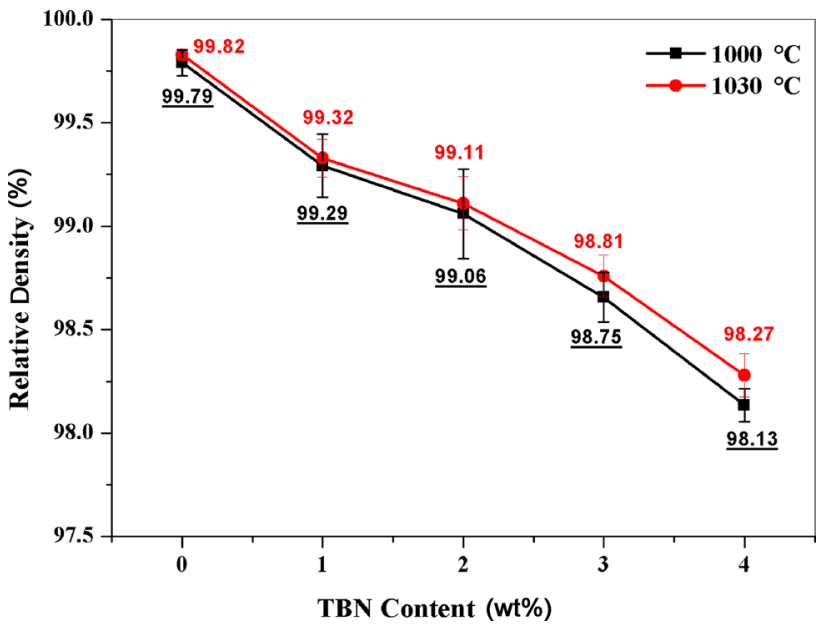

Fig. 4 Relative densities of $\mathrm{Cu} / \mathrm{TBN}$ composites with different TBN contents: filled square: $1000{ }^{\circ} \mathrm{C}$ for $2 \mathrm{~h}$; filled circle: $1030{ }^{\circ} \mathrm{C}$ for $2 \mathrm{~h}$

relative density decreases with the $\mathrm{TiB}_{2} / \mathrm{TiN}$ content increasing. Comparing the two different sintering programs, higher sintering temperature is proved to be helpful to promote the densification.

\subsection{Mechanical Properties}

The hardness of composites, as shown in Fig. 5a, is markedly affected by the $\mathrm{TiB}_{2} / \mathrm{TiN}$ content. As the $\mathrm{TiB}_{2} / \mathrm{TiN}$ content increases from 0 to $4 \mathrm{wt} \%$, the hardness in both groups presents a continuous increase accordingly, which is mostly due to the increasing geometric share of the $\mathrm{TiB}_{2} /$ TiN ceramics [21]. Both $\mathrm{TiB}_{2}$ and $\mathrm{TiN}$ have the extremely high hardness over $30 \mathrm{GPa}$, as a result, the higher $\mathrm{TiB}_{2} / \mathrm{TiN}$ content, the higher hardness of composites. Moreover, the results indicate that higher sintering temperature at $1030{ }^{\circ} \mathrm{C}$ is also helpful to obtain higher hardness probably due to better densification.

Figure $5 b$ shows the effect of $\mathrm{TiB}_{2} / \mathrm{TiN}$ content on the ultimate tensile strength (UTS) of composites sintered at both $1000{ }^{\circ} \mathrm{C}$ and $1030{ }^{\circ} \mathrm{C}$. It can be seen that the UTS increases as the $\mathrm{TiB}_{2} / \mathrm{TiN}$ content increases from 0 to $2 \mathrm{wt} \%$, and reaches the highest value at $2 \mathrm{wt} \%$ (291 MPa for $1000{ }^{\circ} \mathrm{C}$ and $297 \mathrm{MPa}$ for $1030{ }^{\circ} \mathrm{C}$ ). Although the UTS of both groups basically has the same change tendency, the value at $1030{ }^{\circ} \mathrm{C}$ is higher than that at $1000{ }^{\circ} \mathrm{C}$, which can be attributed to the improved $\mathrm{Cu} /$ ceramics interfacial bonding strength and better densification at higher sintering temperature. The stress-strain curves of $\mathrm{Cu} / \mathrm{TBN}$ composites are shown in Fig. 5c, d. It can be seen that the strain is decreased with the $\mathrm{TiB}_{2} / \mathrm{TiN}$ content increasing whether the sintering temperature is $1000{ }^{\circ} \mathrm{C}$ or $1030{ }^{\circ} \mathrm{C}$, and the stress-strain behavior of composites sintered at $1000{ }^{\circ} \mathrm{C}$ and $1030{ }^{\circ} \mathrm{C}$ shows little difference. 

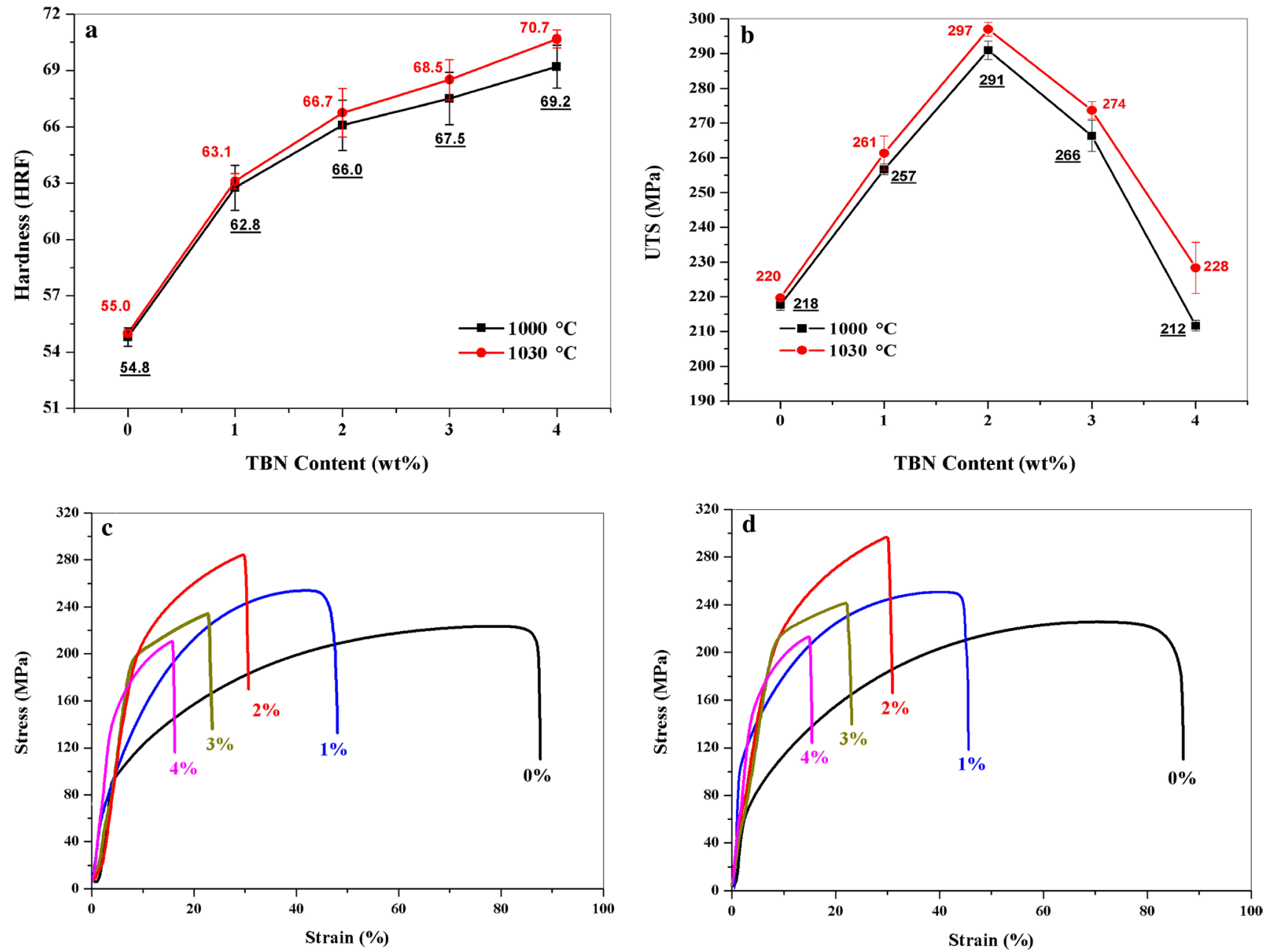

Fig. 5 Hardness a and UTS b of Cu/TBN composites: filled square: $1000{ }^{\circ} \mathrm{C}$ for $2 \mathrm{~h}$; filled circle: $1030{ }^{\circ} \mathrm{C}$ for $2 \mathrm{~h}$. And stress-strain curves of $\mathrm{Cu} / \mathrm{TBN}$ composites sintered at $1000{ }^{\circ} \mathrm{C} \mathbf{c}, 1030^{\circ} \mathrm{C} \mathbf{d}$

\subsection{Strengthening Mechanisms}

Figure 6a-d shows the polished surface of the $\mathrm{Cu} / \mathrm{TBN}$ composites with different contents of $\mathrm{TiB}_{2} / \mathrm{TiN}$. The offwhite areas are detected to be $\mathrm{Cu}$ matrix, and the dark gray areas are the C-CTBN particles fabricated during the SHS process. As the $\mathrm{TiB}_{2} / \mathrm{TiN}$ content increases from 1 to $4 \%$, the dark gray areas cover an increasing proportion. The C-CTBN particles distributed in the matrix are core-shell structured with a $\mathrm{TiB}_{2} / \mathrm{TiN}$ shell and a $\mathrm{Cu} / \mathrm{Ti}$ alloy core (Fig. 6e). As Fig. 6a-d shows, the C-CTBN particles are randomly distributed in the $\mathrm{Cu}$ matrix. Besides the large composite particles, some small particles are also observed to be scattered in the $\mathrm{Cu}$ matrix. These small particles are probably resulted from the rupture of the large CTBN particles during the ball milling process. No aggregation of the C-CTBN particles can be found in the composites.

The reinforcements of $\mathrm{TiB}_{2}$ and $\mathrm{TiN}$ in the composites have a significant effect on the microstructure of the composites. In the composites, a quite high thermal mismatch exists between the $\mathrm{Cu}$ matrix and the $\mathrm{TiB}_{2} / \mathrm{TiN}$ ceramic particles. Thus, during the cooling process after sintering, dislocations formed at the interfaces between $\mathrm{Cu}$ and ceramics (including both $\mathrm{TiB}_{2}$, TiN and residual $\mathrm{BN}$ ) due to the thermal mismatch $[22,23]$. In this manner, thermally induced dislocations result in the "dislocation strengthening" in the $\mathrm{Cu}$ matrix. Considering more interface existing around smaller reinforcement particles for dislocation to take place, a decreased particle size brings about the increased effect of dislocation strengthening [24], thus the TiN particles in the size of about $50 \mathrm{~nm}$ are more effective in strengthening $\mathrm{Cu}$ matrix in the dislocation strengthening manner than the micro-sized $\mathrm{TiB}_{2}$ particles.

Apart from the dislocation strengthening, load transfer from $\mathrm{Cu}$ matrix to reinforcements is also an important strengthening mechanism in the $\mathrm{Cu} / \mathrm{TBN}$ composites. However, the irregular ceramic particles with low aspect ratio are commonly considered not efficient in load transfer [17, 

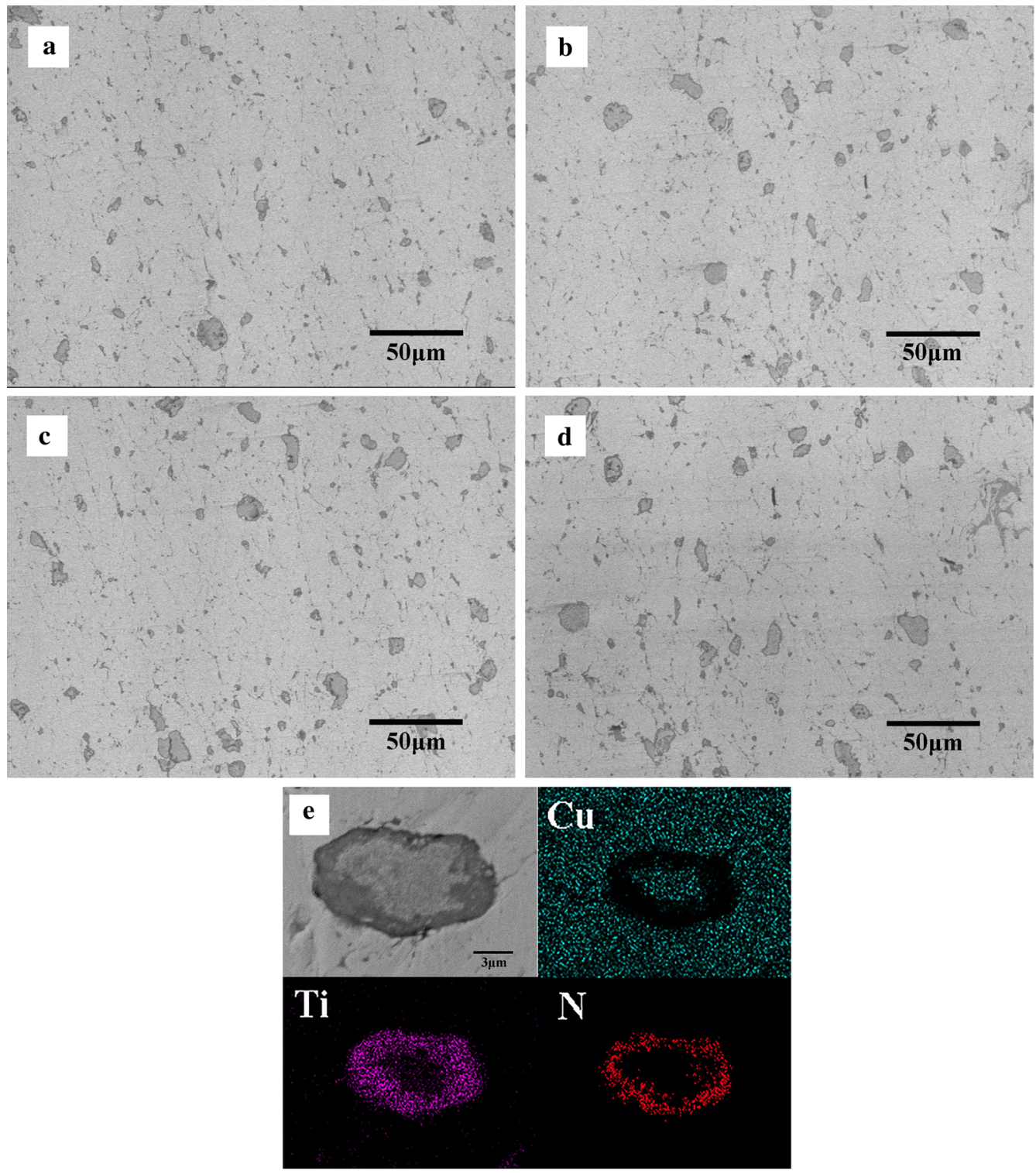

Fig. 6 Distribution of C-CTBN particles in the Cu/TBN composites with different TBN contents: a 1\%, b 2\%, c 3\%, d 4\%; e core-shell structure of C-CTBN composite particles

$18,25]$. In this case, the short clubbed $\mathrm{TiB}_{2}$ particles with higher aspect ratio have an advantage over the TiN particles. As a result, the strengthening effect can be considered as the combined action of both the spherical TiN particles in dislocation strengthening mechanisms and the short clubbed $\mathrm{TiB}_{2}$ particles in load transfer mechanism.

The core-shell structure, in which a $\mathrm{Cu}-\mathrm{Ti}$ alloy core is uniformly covered by a $\mathrm{TiB}_{2} / \mathrm{TiN}$ ceramic shell, is quite an interesting microstructure, which has a different structure with the traditional reinforcements. To evaluate the effect of the core-shell structure on the mechanical properties of $\mathrm{Cu} / \mathrm{TBN}$ composites, a comparative study has been made. Three different kinds of specimens are selected to make the comparison: (a) $\mathrm{Cu}$ without any ceramics reinforcements, (b) $\mathrm{Cu}$ matrix composites reinforced by A-CTBN, and (c) $\mathrm{Cu}$ matrix composites reinforced by C-CTBN. And the $\mathrm{TiB}_{2} /$ TiN content in both (b) and (c) is $2 \mathrm{wt} \%$. Their stress-strain curves are shown in Fig. 7. Cu without any ceramics has the largest strain but the lowest UTS. Composites (c) have the highest UTS and the lowest strain, although both (b) and (c) have the same $\mathrm{TiB}_{2} / \mathrm{TiN}$ contents.

It is commonly accepted that the increase in particle size means the decrease in work hardening and the accelerated damage in the form of particle cracking. As a result, the general view expects that the smaller the particles, the higher the composites strength $[26,27]$. According to this view, 


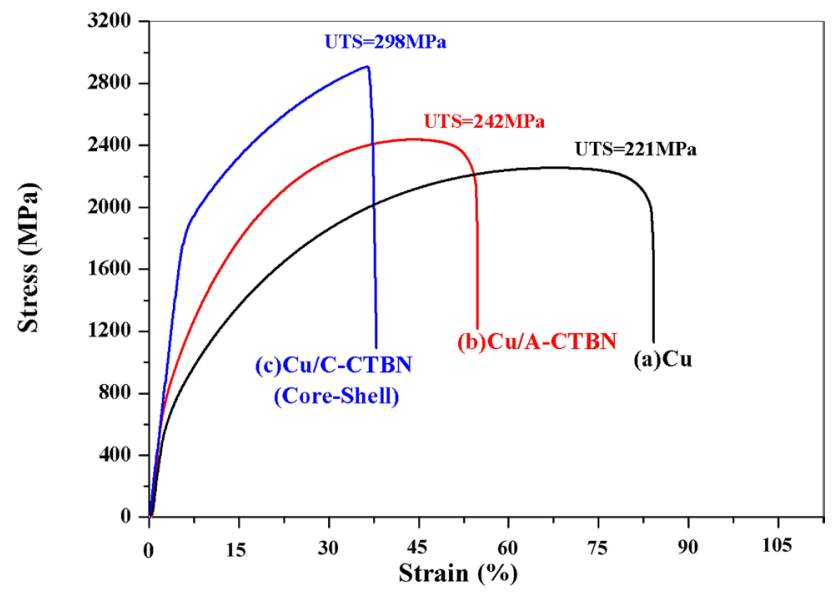

Fig. 7 Comparison of stress-strain curves: (a) $\mathrm{Cu}$ without any ceramics reinforcements, (b) $\mathrm{Cu}$ matrix composites reinforced by A-CTBN, (c) $\mathrm{Cu}$ matrix composites reinforced by $\mathrm{C}-\mathrm{CTBN}$

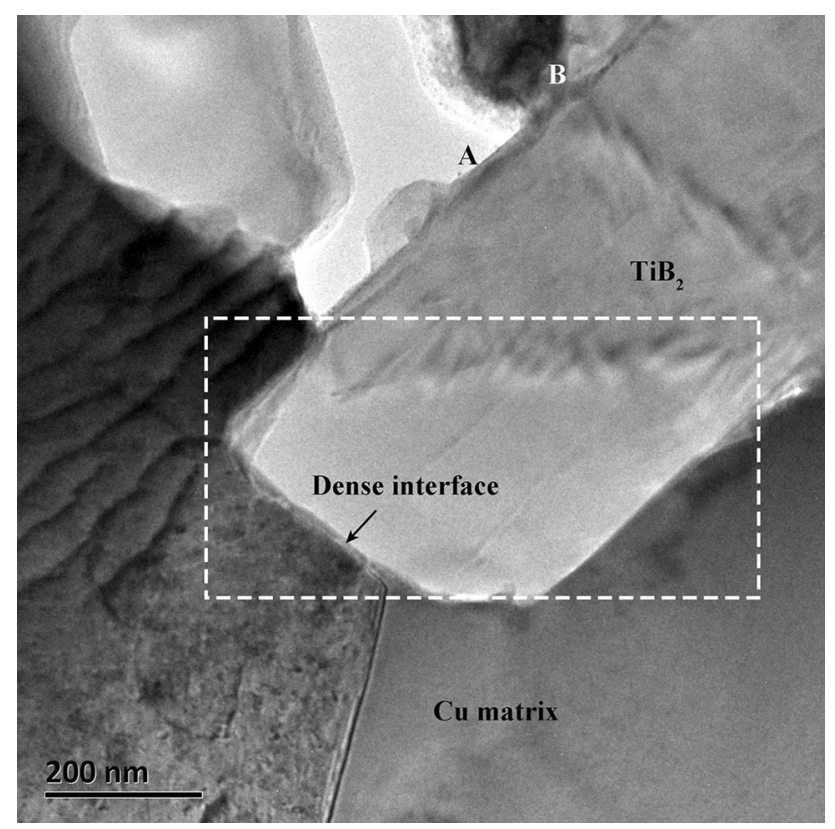

Fig. 8 TBN/Cu interfacial structure

composites (c) should have a lower UTS than (b) because the C-CTBN particle has a much larger size $\left(d_{50}=22 \mu \mathrm{m}\right)$ than the $\mathrm{TiB}_{2}$ (length $\leq 1 \mu \mathrm{m}$, diameter $\leq 0.5 \mu \mathrm{m}$ ) and $\mathrm{TiN}$ $\left(d_{50}=20 \mathrm{~nm}\right)$ in A-CTBN, but the test results are obviously opposite. The abnormal results can be attributed to the improved $\mathrm{Cu} /$ ceramics interfacial bonding and the special core-shell structure.

The improved TBN/Cu interfacial bonding is an important factor of the improvement of UTS. Figure 8 shows the $\mathrm{TBN} / \mathrm{Cu}$ interfacial structure. The $\mathrm{Cu} / \mathrm{TiB}_{2}$ interface in the rectangular box is very tight with almost no gaps. This interface is due to $\mathrm{TiB}_{2}$ buried in molten $\mathrm{Cu}$ during SHS process. For the $\mathrm{TiB}_{2}$ not buried in molten $\mathrm{Cu}$, the $\mathrm{TiB}_{2}$ surface is partly exposed to pores (labeled "A"), and partly forms a weak interface bonding with Cu matrix (labeled "B") due to interface diffusion and it is difficult to have a high interface bonding strength. For group (b), the $\mathrm{Cu}$ /ceramics interfacial bonding is mainly formed by interfacial diffusion, therefore, the interfacial bonding strength is relatively weak, and the interfaces can be easily cracked, thus it is hard to obtain good strengthening effect. However, in the case of group (c), $\mathrm{Cu}$ is instantaneously molten during the SHS process, thus the $\mathrm{TBN} / \mathrm{Cu}$ interfacial wetting is much optimized. It can be observed from Figs. 2, 3 and 8 that some of the $\mathrm{TiB}_{2}$ particles have already firmly buried into the $\mathrm{Cu}$ matrix after the SHS process. These buried particles are hard to be pulled out during the fracture process, which is beneficial to the improvement of tensile strength.

Load transfer mechanism can be descripted as following [24]: the load is transferred from the weaker matrix, across the matrix/reinforcement interface, to the typically stiffer reinforcement when the composites are under an applied load, and the strengthening take place by the reinforcement "carrying" much of the applied load. The stress transferred to the particles is gradually accumulated to the maximum in middle part of the particles. If the stress is accumulated to be higher than the fracture strength of the ceramic particles, the particle fracture happens. However, due to the low aspect ratio of particulate materials and low ceramics/metal interfacial bonding strength, load transfer is not efficient, and the stress accumulated on the particles is far below the fracture strength of the ceramics. As a result, it is usually the ceramics/metal interfaces debonding rather than the particles crack. In other words, the strengthening potential is not explored sufficiently. But it is quite different for the core-shell particles. On one side, the load can be transferred to the $\mathrm{TiB}_{2} / \mathrm{TiN}$ ceramics like the case in the particle reinforced composites; on the other side, it can be further transferred from the $\mathrm{TiB}_{2} / \mathrm{TiN}$ ceramics shells to the $\mathrm{Cu}-\mathrm{Ti}$ alloy inner cores. Since plenty of ceramic particles, especially the clubbed $\mathrm{TiB}_{2}$ particles, are firmly buried into the $\mathrm{Cu}$ matrix, the core-shell structure can act as a unit. The load transferred to the $\mathrm{Cu}-\mathrm{Ti}$ alloy core can be accumulated to quite high level without rupture because the alloy can tolerate a certain strain to release the stress concentration. The load bared by the core-shell particles is summation of both $\mathrm{TiB}_{2} / \mathrm{TiN}$ ceramic particles and the $\mathrm{Cu}-\mathrm{Ti}$ alloy core, thus the UTS of composites is obviously elevated.

Although the UTS is increased due to the strengthening effect of the $\mathrm{TiB}_{2} / \mathrm{TiN}$ ceramics, the elongation of the $\mathrm{Cu} /$ TBN composites is decreased as shown in Fig. 7. As mentioned above, the $\mathrm{TiB}_{2} / \mathrm{TiN}$ ceramics mostly exist around $\mathrm{Cu} / \mathrm{Ti}$ alloy cores, so these regions present more brittleness than plasticity. During the tensile process, despite the 
deformation of $\mathrm{Cu} / \mathrm{Ti}$ alloy cores can endure some strain to release the stress concentration, the brittle regions cannot deform as large as the $\mathrm{Cu}$ matrix, so these regions are usually fractured former than the $\mathrm{Cu}$ matrix. As a result, higher reinforcement content means more sources of the cracks in the brittle regions, and the elongation of the composites is decreased accordingly.

The fractured micrographs of the tensile samples for the pure $\mathrm{Cu}$ and $\mathrm{Cu} / \mathrm{TBN}$ composites with $2 \mathrm{wt} \% \mathrm{TiB}_{2} / \mathrm{TiN}$ have been examined using SEM as shown in Fig. 9. The fractured morphology of $\mathrm{Cu}$ is mostly ductile morphology of dimples. However, in the $\mathrm{Cu} / \mathrm{TBN}$ composites as shown in Fig. 8c, the ductile morphology is not as obvious as it in the $\mathrm{Cu}$, and plenty of micro-ceramic particles appear on the fractured surface, which is the typical feature of brittle fracture. Despite this, some ductile features in the form of dimples are also observed due to the localized deformation on the fractured surface (Fig. 8d). It can be concluded that the fracture of $\mathrm{Cu} / \mathrm{TBN}$ composites is a complex process of both brittle fracture and ductile fracture, which is similar with some other MMCs [28, 29].

The fracture process can be described as follows. The discontinuous crack is accumulated ahead of the continuous crack tip, which results in the micro-crack extension. The crack propagates when these micro-cracks are connected by micro-void coalescence, which explains the dimpled appearance of the fracture surface [30]. However, due to the different thermal expansions of the $\mathrm{TiB}_{2} / \mathrm{TiN}$ ceramics and $\mathrm{Cu}$ matrix during the cooling process after sintering, it can bring about the tensile triaxial stress state around the ceramic particles. Once the crack propagates to these areas, it can be deflected around the $\mathrm{TiB}_{2} / \mathrm{TiN}$ particles [31]. Hence then, it is hard to generate the long path cracks, and the dimples in $\mathrm{Cu} / \mathrm{TBN}$ composites only exist in micro-area.

\section{Conclusion}

The $\mathrm{Cu} / \mathrm{TBN}$ composites with improved tensile strength and hardness were prepared using CTBN particles as the reinforcements. The strengthening effect was considered as the combined action of both the spherical TiN particles in dislocation strengthening mechanisms and the short clubbed $\mathrm{TiB}_{2}$ particles in load transfer mechanisms. Moreover, the CTBN particles exhibited better strengthening effect than the traditional ceramic particles, which was mainly attributed to the special core-shell structure and the enhanced interfacial bonding strength. The highest UTS and hardness reached up to $297 \mathrm{MPa}$ and $70.7 \mathrm{HRF}$, respectively. The fracture of $\mathrm{Cu} /$

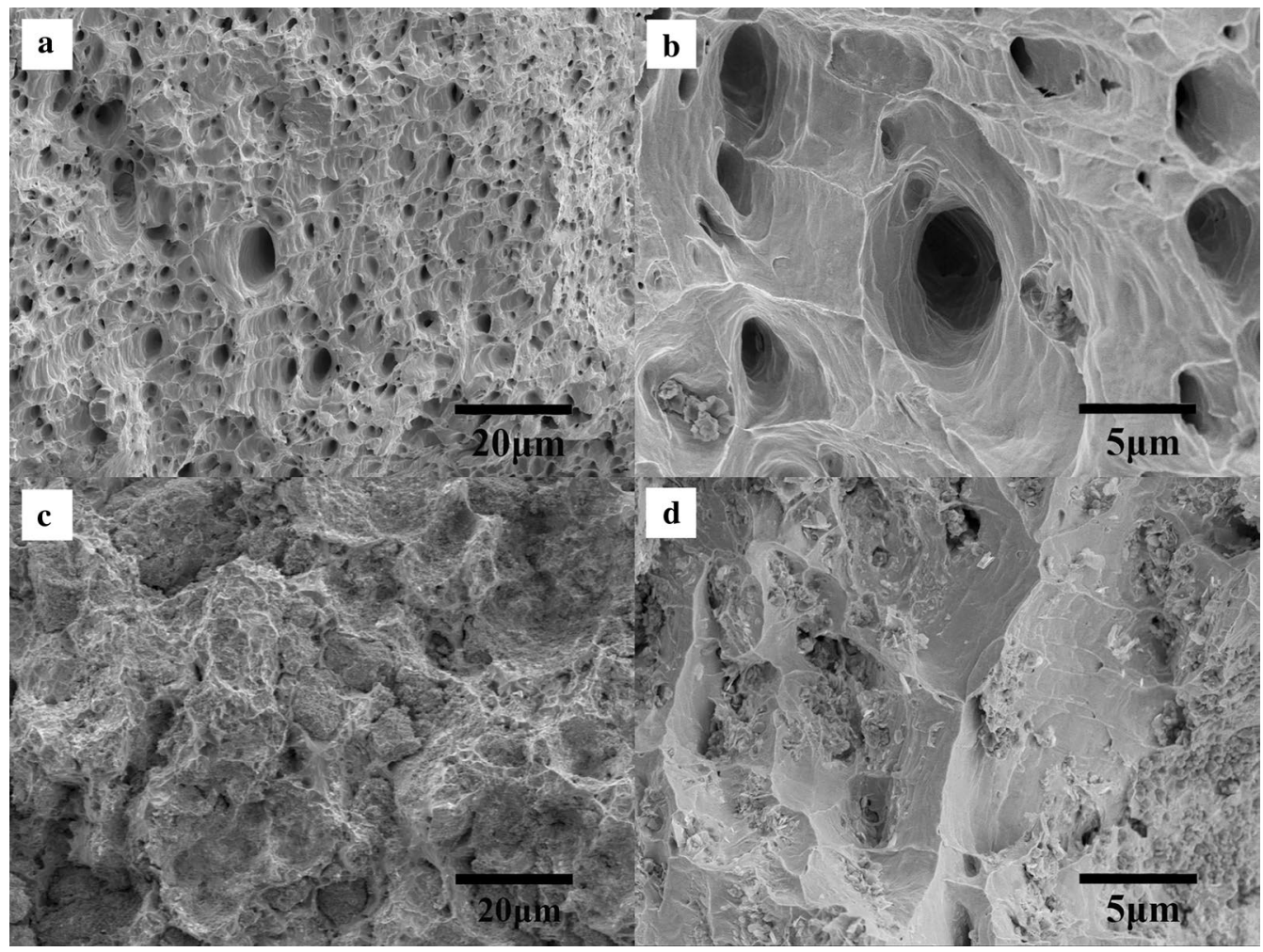

Fig. 9 Fractured surface micrographs of specimens: a, b Cu; c, d Cu/TBN composites (Cu/C-CTBN) with 2 wt\% TiB $2 / \mathrm{TiN}$ ceramics. All specimens were sintered at $1030{ }^{\circ} \mathrm{C}$ for $2 \mathrm{~h}$ 
TBN composites was a complex process of both brittle fracture in the macroscale and ductile fracture in the microscale.

Acknowledgements This work was financially supported by the National Key R\&D Program of China (No. 2018YFF01013605), the National Natural Science Foundation of China (No. 51501215), the Youth Innovation Promotion Association CAS (No. 2019254), the Science Foundation for Youth Scholar of State Key Laboratory of High Performance Ceramics and Superfine Microstructures (No. SKL201701), the State Key Laboratory of New Ceramic and Fine Processing Tsinghua University (No. KF201806).

\section{References}

[1] M. Guo, K. Shen, M. Wang, Acta Mater. 57, 4568 (2009)

[2] S. Sharma, T. Nanda, O.P. Pandey, Ceram. Int. 44, 104 (2018)

[3] P. Zhang, J. Jie, H. Li, T. Wang, T. Li, J. Mater. Sci. 50, 3320 (2015)

[4] B.-W. Ahn, J.-H. Kim, K. Hamad, S.-B. Jung, J. Alloys Compd. 693, 688 (2017)

[5] A. Jha, S.J. Yoon, J. Mater. Sci. 34, 307 (1999)

[6] T. Aizawa, T. Akhadejdamrong, C. Iwamoto, Y. Ikuhara, A. Mitsuo, J. Am. Ceram. Soc. 85, 21 (2002)

[7] Y. Zhan, G. Zhang, J. Mater. Sci. 40, 223 (2005)

[8] D.M. Jarzabek, M. Milczarek, T. Wojciechowski, C. Dziekonski, M. Chmielewski, Ceram. Int. 43, 5283 (2017)

[9] J. Yin, D. Yao, Y. Xia, K. Zuo, Y. Zeng, J. Alloys Compd. 615, $983(2014)$

[10] C. Zhang, J. Yin, D. Yao, K. Zuo, Y. Xia, H. Liang, Y. Zeng, Compos. Part A Appl. Sci. Manuf. 102, 145 (2017)

[11] J. Li, F. Li, K. Hu, Y. Zhou, J. Alloys Compd. 334, 253 (2002)
[12] J.H. Shim, J.S. Byun, Y. Whan Cho, Scr. Mater. 47, 493 (2002)

[13] M. Kitiwan, A. Ito, T. Goto, J. Eur. Ceram. Soc. 34, 197 (2014)

[14] C.L. Yeh, C.H. Chiang, Ceram. Int. 41, 11287 (2015)

[15] B. Chen, Q. Bi, J. Yang, Y. Xia, J. Hao, Mater. Sci. Eng. A 491, $315(2008)$

[16] G.J. Zhang, Z.Z. Jin, X.M. Yue, J. Am. Ceram. Soc. 78, 2831 (1995)

[17] Y.F. Yang, H.Y. Wang, Y.H. Liang, R.Y. Zhao, Q.C. Jiang, Mater. Sci. Eng. A 445-446, 398 (2007)

[18] Z. Xinghong, Z. Chuncheng, Q. Wei, H. Xiaodong, V.L. Kvanin, Compos. Sci. Technol. 62, 2037 (2002)

[19] S. Cho, K. Kikuchi, T. Miyazaki, K. Takagi, A. Kawasaki, T. Tsukada, Scr. Mater. 63, 375 (2010)

[20] Y. Zhang, H.L. Zhang, J.H. Wu, X.T. Wang, Scr. Mater. 65, 1097 (2011)

[21] Y.A. Lu, J.F. Yang, W.Z. Lu, R.Z. Liu, G.J. Qiao, C.G. Bao, Mater. Sci. Eng. A 527, 6289 (2010)

[22] J.N. Wei, Z.B. Li, F.S. Han, Phys. Status Solidi A 191, 125 (2002)

[23] W.D. Fei, M. Hu, C.K. Yao, Mater. Chem. Phys. 77, 882 (2003)

[24] N. Chawla, Y.L. Shen, Adv. Eng. Mater. 3, 357 (2001)

[25] N. Xu, Y.P. Zong, F.Z. Hang, L. Zuo, Acta Metall. Sin. (in Chinese) 43, 863 (2007)

[26] S.V. Kamat, A.D. Rollett, J.P. Hirth, Scr. Metall. Mater. 25, 27 (1991)

[27] M.T. Kiser, F.W. Zok, D.S. Wilkinson, Acta Mater. 44, 3465 (1996)

[28] P. Jin, X.B. Lv, Q.Z. Wang, Z.Y. Ma, Y. Liu, S. Li, Acta Metall. Sin. (in Chinese) 47, 298 (2011)

[29] Q.K. Cai, C.L. He, M.J. Zhao, J. Bi, C.S. Liu, Acta Metall. Sin. (in Chinese) 39, 865 (2003)

[30] Y. Flom, R.J. Arsenault, Acta Metall. 37, 2413 (1989)

[31] L. Cao, C.P. Jiang, Z.K. Yao, T.Q. Lei, Acta Metall. Sin. (in Chinese) 25, 113 (1989) 